\title{
Drowning fatalities in childhood: the role of pre-existing medical conditions
}

\author{
Richard C Franklin, ${ }^{1,2}$ John H Pearn, ${ }^{1,2,3}$ Amy E Peden ${ }^{1,2}$
}

${ }^{1}$ Royal Life Saving Society Australia, Broadway, New South Wales, Australia

${ }^{2}$ College of Public Health, Medical and Veterinary Sciences, James Cook University, Townsville, Queensland, Australia

${ }^{3}$ Lady Cliento Children's Hospital, Brisbane, Queensland, Australia

\section{Correspondence to} Dr Richard C Franklin, College of Public Health, Medical and Veterinary Sciences, James Cook University, Building 41 Room 213, Townsville, Qld 4811 Australia;

richard.franklin@jcu.edu.au

Received 11 January 2017 Revised 23 March 2017

Accepted 17 April 2017 Published Online First 8 May 2017

\section{SLinked}

- http://dx.doi.org/10.1136/ archdischild-2017-313427

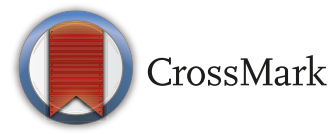

To cite: Franklin RC, Pearn JH, Peden AE. Arch Dis Child

2017; 102:888-893.

\section{ABSTRACT}

Objectives This study is an analysis of the contribution of pre-existing medical conditions to unintentional fatal child (0-14 years) drowning and a of critique prevention stratagems, with an exploration of issues of equity in recreation.

Design This study is a total population, cross-sectional audit of all demographic, forensic and on-site situational details surrounding unintentional fatal drowning of children 0-14 years in Australia for the period of 1 July 2002 to 30 June 2012. Data were sourced from the National (Australia) Coronial Information System. Age-specific disease patterns in the general population were obtained from the Australian Institute of Health and Welfare.

Results Four hundred and sixty-eight children drowned during the study period. Fifty-three (11.3\%) had a pre-existing medical condition, of whom 19 suffered from epilepsy, 13 from autism and 5 with non-specific intellectual disabilities. Epilepsy is a risk factor in childhood drowning deaths, with a prevalence of $4.1 \%$ of drowning fatalities, compared with $0.7 \%-1.7 \%$ among the general $0-14$ years population (relative risk: 2.4-5.8). Epilepsy was deemed to be contributory in 16 of 19 cases (84.2\% of epilepsy cases) with a median age of 8 years. Asthma and intellectual disabilities were under-represented in the drowning cohort.

Conclusion Except for epilepsy, this research has indicated that the risks of drowning while undertaking aquatic activities are not increased in children with preexisting medical conditions. Children with pre-existing medical conditions can enjoy aquatic activities when appropriately supervised.

\section{INTRODUCTION}

Drowning remains a major cause of childhood mortality worldwide, ${ }^{1}$ in both developed and developing nations. ${ }^{2}$ In Australia, children are the age group most at risk of unintentional drowning. ${ }^{3}$ Supervision that is constant, proximate and undertaken by an adult is understood to be the most effective drowning prevention strategy for children. ${ }^{4}$

Statistical and epidemiological studies that report drowning fatalities use 'death by immersion' as the primary designator for case finding and victim identification. ${ }^{2}$ These crude statistics mask more than 15 defined syndromes that are included under the broad term 'drowning'. 5 These disparate syndromes range from the infant who drowns in the family bathtub ${ }^{6}$ to the rescuer who drowns while attempting to rescue a child. ${ }^{7}$ It has long been known that to be effective, advocacy and interventions to reduce preventable drowning in childhood

\section{What is already known on this topic?}

Children are the age group most at risk of unintentional fatal drowning.

- Medical conditions such as epilepsy are believed to increase drowning risk.

\section{What this study adds?}

- Epilepsy increases the relative risk (2.4-5.8) of drowning in childhood, with a prevalence of $4.1 \%$ of drowning deaths, compared with $0.7 \%-1.7 \%$ among the general population.

- No other identified pre-existing medical conditions were associated with an increased risk of drowning.

- Heightened supervision of children around water is always warranted, including those with pre-existing medical conditions. A higher level of supervision is required for those with epilepsy.

must focus on each distinct victim-site-scenario drowning syndrome. ${ }^{589}$

The question arises whether pre-existing medical conditions, such as epilepsy or physical disability, contribute to childhood drowning. In addition to the planning for effective preventative stratagems, this issue has implications relating to equality of opportunity and equity of access to aquatic activities for children with disabilities. ${ }^{10}$ Several papers have highlighted what are believed to be the increased risks of pre-existing medical conditions and drowning, particularly epilepsy. ${ }^{11-16}$ In publications sourced from many nations, including those compiled by the Royal Life Saving Society Australia (RLSSA), there are recurring reports of children who have also suffered from pre-existing medical conditions whose deaths are included in the drowning statistics. ${ }^{17-20}$

The crucial question for future preventative and public health programmes is whether pre-existing medical conditions are primarily causal, leading to fatality, or are contributory factors conferring increased risk or are simply associative. There is a paucity of international studies concerning the contributory causal or associative specificity of pre-existing medical conditions leading to drowning. The answer to this question necessitates a total population survey, with an analysis of each individual child drowning fatality—set against the 
perspective of the population incidence of specific childhood medical conditions. ${ }^{21-24}$

In this paper, we report such an audit comprising a 10 -year (2002-2012) national population study of every unintentional childhood drowning fatality occurring in Australia. In this study, we have linked each drowning with both a forensic review and an analysis of each child's medical history.

\section{Aims}

The aims of this paper are to:

- describe the contribution of pre-existing medical conditions leading to child (0-14 years) drowning

- critique stratagems for the prevention of drowning among children with pre-existing medical conditions

- explore issues of equality of aquatic recreation.

\section{METHODS}

This total population study analysed the details of every child (0-14 years) who died from unintentional drowning in Australia between 1 July 2002 and 30 June 2012.

\section{Definitions}

A child was defined as an individual $0-14$ years of age. This age group was chosen as drowning deaths and medical conditions in Australia are reported using 5-year age bands (eg, 0-4 years, 5-9 years and 10-14 years). Drowning has been defined using the international definition adopted by the WHO. ${ }^{25}$

\section{Case finding}

Under each state's and territory's legislation, drowning fatalities in Australia must be notified to the coroner by the doctor certifying death. In Australia, a nationwide coronial database is a confidential register of all deaths deemed unexpected or unnatural by the certifying doctor. ${ }^{26}$ This is a total population audit of child unintentional fatal drowning in Australia using the National (Australia) Coronial Information System (NCIS) as the primary dataset. From this, RLSSA has generated a National Fatal Drowning Database. This complete, total population database is the gold standard of unintentional drowning deaths in Australia. Cases in the database are routinely cross-referenced against the NCIS and updated as cases become closed (ie, are no longer under investigation by a coroner). Data in this study are correct as at 7 December 2016.

\section{Exclusions}

All cases of aquatic death THAT were not due to drowning (eg, shark or crocodile attack, boating injuries due to physical trauma, and so on) were excluded. Cases identified as self-inflicted harm, homicide, infanticide or the result of assaults were also excluded. Cases were included: even when no body was recovered or where only skeletal remains were found, and cases that did not have a coronial ruling at the time of analysis but where the interim cause of death was stated as drowning. At the time of analysis, $97.2 \%$ of child drowning cases used within this study were closed within the NCIS system. Perusal of the stillopen cases $(2.8 \%)$ suggests these are in no way atypical of the overall database.

\section{Medical reviews}

One of the authors (JP) reviewed the medical details of each case. Details of every drowning scenario, rescue, resuscitation and pre-existing medical condition were reviewed. We defined a pre-existing medical condition as one recorded in the medical history of the victim, obtained from: (A) initial police reports of the fatality; (B) from the report of the attending forensic pathologist undertaking the coronial autopsy; and (C) details from transcripts or findings of subsequent coronial inquests. For children with two or more pre-existing medical conditions $(5.7 \%)$, only the leading condition was coded and used for analysis.

\section{Causal links}

For every case, two of the authors (JP and RF) together formed a collaborative interpretative judgement concerning whether the pre-existing medical condition: (A) was the direct cause of death due to drowning (eg, an epileptic seizure in the water); or (B) compromised (with fatal conclusion) any aspect of an otherwise effective rescue or successful resuscitation; or (C) was incidental to the circumstances of the drowning incident or its fatal outcome.

\section{Data analysis and ethics}

Data were recorded and reviewed for each victim's age, sex, medical history, date of incident, date of death (if different to incident in the cases of initial non-fatal drowning), remoteness classification of drowning location, type of water hazard (eg, river, bathtub and beach), activity at time of death, visiting status, country of birth, Aboriginal and/or Torres Strait Islander status and the presence of alcohol revealed by forensic autopsy. The prevalence of relevant medical conditions in the population of Australian children 0-14 years was obtained from data published by the Australian Institute of Health and Welfare ${ }^{24-29}$ and The Lancet. $^{30}$ Data from the US Department of Education ${ }^{31}$ was used as a proxy for Australia for the prevalence of neuromuscular disease and paralysis as no equivalent data was available for Australia. Data analysis was undertaken using IBM SPSS. ${ }^{32}$ Relative risk was calculated using the MedCalc statistical software. ${ }^{33}$

This study was approved by the Department of Justice and Regulation Human Research Ethics Committee (JHREC) (CF/07/13729; CF/10/25057, CF/13/19798).

\section{RESULTS}

There were 2896 unintentional drowning deaths in Australia between 1 July 2002 and 30 June 2012. Of these, 468 (16.2\%) were children ( $0-14$ years) and 53 (11.3\% of all fatal child drownings) had an identified pre-existing medical condition, with an average of 5.3 deaths per annum (figure 1). Males accounted for $64.7 \%$ of all childhood drowning fatalities; however, males and females were equality represented within the cohort with pre-existing medical conditions ( $\mathrm{m}: 11.6 \%$;: $10.9 \%$ ). Nineteen victims (35.8\%) were aged 0-4 years, 20 (37.7\%) were aged 5-9 years and $14(26.4 \%)$ were aged $10-14$ years (table 1$)$.

Fifty-three children suffered from a pre-existing medical condition (table 2). Children with pre-existing medical conditions were on average older ( 7.0 years) than those children without pre-existing medical conditions (3.7 years). Children with pre-existing medical conditions drown in similar circumstances to those without. Children with pre-existing medical conditions commonly drowned in swimming pools $(32.1 \%)$, bathtubs and rivers (18.9\% respectively), as a result of falls into water (49.1\%) and while swimming (22.6\%) and bathing (20.8\%). Location of drowning and activity prior to drowning were not found to be statistically significant for children with pre-existing medical conditions.

Alcohol was found to be present in 3.8\%, though it was not found to be statistically significant. Four victims were known to be Aboriginal and/or Torres Strait Islander. Almost half (43.4\%) 


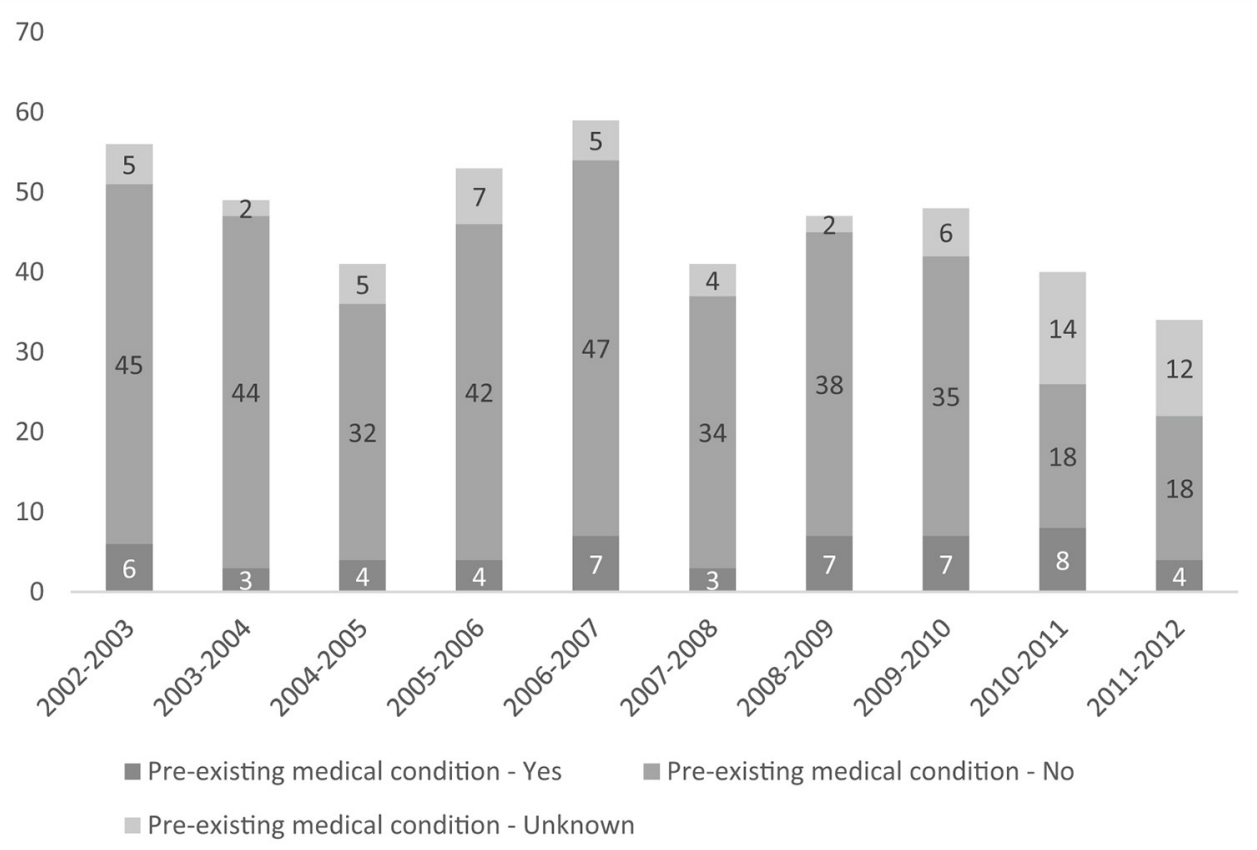

Figure 1 Child (0-14 years) drowning deaths and status of pre-existing medical conditions, by financial year. Total population survey, Australia, 2002/03-2011/12 ( $N=468)$.

of drowning deaths occurred in areas classified as major cities, with a further $7.5 \%$ taking place in remote and very remote locations. The majority of victims $(86.8 \%)$ were not visitors.

Children with epilepsy (35.8\%) included those with primary diagnoses of a seizure disorder, Landau Kleffner Syndrome, persistent febrile convulsions and Lennon-Gastaut syndrome. Other medical conditions (11.4\%) included diagnoses such as Down syndrome, cystic fibrosis, fetal alcohol syndrome and Duchenne muscular dystrophy. Epilepsy is an associated risk factor in childhood drowning deaths, with a prevalence of $4.1 \%$, compared with a prevalence of $0.7 \%-1.7 \%$ among the general 0-14 years age population (RR: $2.4-5.8$ (95\% CI 1.3 to 13.7 )). The median age of children who drowned with a diagnosis of pre-existing epilepsy was 8 years (range $2-14$ years).

Intellectual disabilities (RR: $0.2 ; 95 \%$ CI 0.1 to 0.6 ) and asthma (RR: $0.05-0.09$; $95 \%$ CI 0.0 to 0.3 ) were associated with a lower risk of drowning than that in the general population.

The analysis and interpretation of the links between pre-existing medical conditions and fatal drowning are shown in table 3 . In 16 children $(30.2 \%$ of the 53 children with an identified pre-existing medical condition), their pre-existing medical condition had no impact on the drowning event. For example, the fact that a toddler had cystic fibrosis was incidental to his wandering away from a family picnic and drowning in an ornamental pond nearby (table 3 ).
One child had Down syndrome, and another was developmentally delayed (and suffered epilepsy), which we deemed contributory to the drowning. We deemed several pre-existing conditions other than epilepsy (eg, autism, intellectual disability, neuromuscular disease and myocarditis) possibly or directly contributory to the drowning in 20 cases. No child with cerebral palsy, uncomplicated by epilepsy or other condition drowned.

Among the 16 victims where epilepsy was deemed to be a direct cause: 14 were born in Australia (the country of birth was unrecorded in two cases). Two children were identified as of Aboriginal and/or Torres Strait Islander descent. None were overseas visitors. Two-fifths (43.8\%) were aged 10-14 years, with only one victim under 5 years of age. Five children were in a bathtub and bathing at the time (aged 3-14 years), five were in swimming pools, two were at the beach, two were in rivers, one was in a lake and one in a dam (table 4). None were appropriately supervised at the time.

\section{Discussion}

In this study, $11 \%$ of all childhood unintentional drowning victims had an identified pre-existing medical condition; this was lower than that which was found by Schyllander et al $(16 \%) .{ }^{34}$ Similar to other studies, two-thirds $(65 \%)$ of childhood drowning fatalities were male ${ }^{34} 35$; however, males and

Table 1 Patterns of pre-existing medical conditions, by age and sex. Total population survey of all child drowning deaths, Australia, 2002/03$2011 / 12(\mathrm{~N}=468)$

\begin{tabular}{|c|c|c|c|c|c|c|c|c|c|c|c|c|c|}
\hline \multirow[b]{2}{*}{$\begin{array}{l}\text { Pre-existing medical } \\
\text { condition(s) }\end{array}$} & \multicolumn{3}{|c|}{ 0-4 Years } & \multicolumn{3}{|c|}{ 5-9 Years } & \multicolumn{3}{|c|}{ 10-14Years } & \multicolumn{3}{|c|}{ Pre-existing medical condition(s) } & \multirow[t]{2}{*}{ Total drowning } \\
\hline & Yes & No & Unknown & Yes & No & Unknown & Yes & No & Unknown & Yes & No & Unknown & \\
\hline Male & 13 & 168 & 24 & 13 & 42 & 7 & 9 & 22 & 5 & 35 & 232 & 36 & 303 \\
\hline Female & 6 & 93 & 20 & 7 & 14 & 4 & 5 & 14 & 2 & 18 & 121 & 26 & 165 \\
\hline Total & 19 & 261 & 44 & 20 & 56 & 11 & 14 & 36 & 7 & 53 & 353 & 62 & 468 \\
\hline
\end{tabular}


Table 2 Drowning deaths of children with pre-existing medical conditions, by diagnosis, age, sex and incidence. Total population survey, Australia, $2002 / 03-2011 / 12(n=53)$

\begin{tabular}{|c|c|c|c|c|c|c|c|c|c|c|}
\hline & $\mathrm{N}$ & Sex & & $\begin{array}{l}\text { Age } \\
\text { (years) }\end{array}$ & $\begin{array}{l}\text { Prevalence/drowning } \\
\text { deaths }\end{array}$ & $\begin{array}{l}\text { General population } \\
\text { prevalence } 0-14 \text { years }\end{array}$ & $\begin{array}{l}\text { Relative } \\
\text { Risk (RR) }\end{array}$ & $\begin{array}{l}\text { RR Confidence } \\
\text { Interval (Cl) }\end{array}$ & $\begin{array}{l}\text { RR statistical } \\
\text { significance }\end{array}$ & References \\
\hline & & M & $\mathbf{F}$ & md & $\%$ & $\%$ & & & & \\
\hline Epilepsy & 19 & 10 & 9 & 8 & 4.1 & $0.7-1.7$ & $2.4-5.8$ & 1.3 to 13.7 & $p<0.001$ & 2741 \\
\hline $\begin{array}{l}\text { Autism, psychological } \\
\text { adjustment problems }\end{array}$ & 13 & 11 & 2 & 5 & 2.8 & 2.4 & 1.2 & 0.6 to 2.3 & $p=0.667$ & 24 \\
\hline Intellectual disabilities & 5 & 4 & 1 & 5 & 1.1 & 4.3 & 0.2 & 0.1 to 0.6 & $p<0.01$ & 28 \\
\hline Asthma & 4 & 2 & 2 & 5.5 & 0.9 & $10.0-15.1$ & $0.05-0.09$ & 0.0 to 0.3 & $p<0.001$ & 242829 \\
\hline $\begin{array}{l}\text { Neuromuscular disease, } \\
\text { paralysis }\end{array}$ & 2 & 2 & 0 & 11 & 0.4 & 0.2 & 2.1 & 0.3 to 14.9 & $p=0.458$ & 31 \\
\hline Total & 53 & 35 & 18 & 7 & 11.3 & & & & & \\
\hline
\end{tabular}

females are equally represented within the cohort with pre-existing conditions. Children with epilepsy commonly drowned in aquatic environments in and around the home, such as bathtubs (31\%) and swimming pools (31\%), and none were adequately supervised at the time of their drowning.

At the outset of this research, we posited that pre-existing medical conditions increase the risk of fatal drowning by one or more of three mechanisms: (A) the pre-existing condition (eg, autism $)^{36}$ might increase the likelihood of a child inappropriately seeking and entering a water hazard; (B) the condition might increase the risk of drowning once the potential victim is in the water (eg, frailty or muscular paresis or paralysis); or (C) reduced rates of successful resuscitation or successful intensive care outcomes due to pre-existing medical conditions (eg, cystic fibrosis).

In the context of current supervisory practices that relate to children with pre-existing medical conditions, this study has confirmed that there is no increased risk for children with delayed social and intellectual development. Rather, intellectual disabilities and asthma were associated with a lower risk of drowning than that in the general population. We posit that this association is related to decreased exposure to aquatic hazards and to instinctive heightened supervision of children. ${ }^{10}$ This applies particularly to frailty, due to sarcopenia particularly of neuromuscular diseases. We believe that this is one reason why this research has not revealed an increased risk to such children, apart from those with epilepsy. An assessment of the mathematical increase in risk necessitates the compilation of exposure denominators that are unknown and probably unknowable for this group of conditions. Children with a priori medical condition may not have had an equal opportunity for swimming lessons ${ }^{30}$ and as such might be at greater risk of drowning. The

Table 3 Attributed pre-existing medical conditions. Total population survey, Australia, 2002/03-2011/12 ( $n=53)$

\begin{tabular}{lcccc}
\hline & $\begin{array}{l}\text { Direct } \\
\text { cause }\end{array}$ & $\begin{array}{l}\text { Possible } \\
\text { contributory }\end{array}$ & No impact & Total \\
\hline Epilepsy & 16 & 1 & 2 & 19 \\
$\begin{array}{l}\text { Autism, psychological } \\
\text { adjustment problems }\end{array}$ & 0 & 12 & 1 & 13 \\
$\begin{array}{l}\text { Intellectual disabilities } \\
\text { Other medical syndromes }\end{array}$ & 2 & 2 & 1 & 5 \\
Asthma & 0 & 0 & 8 & 10 \\
Neuromuscular disease, & 1 & 0 & 4 & 4 \\
paralysis & 1 & & 0 & 2 \\
Total & 21 & 16 & 16 & 53 \\
\hline
\end{tabular}

only pre-existing condition that leads to an increased risk of fatal drowning, under current real-life conditions of supervision, once a child is in the water, is epilepsy. Again, there is a relative increase but the absolute mathematical risk remains small and maybe zero with compensatory supervision. ${ }^{5}$ We posit that multiple, pre-existing medical conditions, specifically associated with epilepsy, may contribute to the risk of drowning, further work is required to elucidate this point.

In the aquatic domain, there are obvious extra demands in the care and supervision of an individual child with a history of epilepsy, or in other conditions such as those with a family history of the long QT (QT) syndrome. ${ }^{37}$ No appropriately supervised child drowned in Australia over the 12-year survey period. Supervision is a complex skill requiring the four elements of proximity, continuity, attention and preparedness for it to be effective. ${ }^{8}$ Children with epilepsy may swim with safety if (A) anti-convulsant drug blood concentrations are in the therapeutic range; (B) the child has been seizure free for 6-12 months; and (C) compensatory extra supervision is in place. ${ }^{5}$

Advocacy for, and the implementation of, safety barriers (ie, barriers that prevent access) around water hazards (especially domestic pools and ponds), have dramatically reduced the rates of childhood drowning. ${ }^{898}$ Such safety barriers are particularly important in the prevention of drowning if children have pre-existing medical conditions especially frailty from any cause and those with intellectual disability.

If rescuers are trained in cardiopulmonary resuscitation, there is a $30 \%-40 \%$ chance of turning a potential fatality into a survivor. ${ }^{11} 39$ Every parent should have a current first aid certificate, a policy of significance for parents of children with disabilities. Swimming skills are important life skills; and children with chronic medical conditions and congenital disabilities need these no less than able bodied children. ${ }^{10}$ Common sense indicates that swimming lessons should be conducted as a one-on-one format and appropriate strategies implemented to ensure the child's safety in the water. ${ }^{10}$ Life jackets, for children at increased risk of a seizure, that will roll them onto their back and keep their nose and mouth out of the water during a seizure may prevent drowning. ${ }^{40}$

This study is the first longitudinal total population analysis of the prevalence and role of pre-existing medical conditions in unintentional fatal drowning among children aged 0-14 years using unselected, total population coronial data. The use of coronial data allows for a deeper understanding of the presence of pre-existing medical conditions as identified by forensic pathologists by accessing coronial autopsy reports. There were a small number (13.2\% of all unintentional child fatal drownings) of cases where pre-existing medical condition was unknown. This was due to no information being available about the status of the pre-existing 
Table 4 Location grouping by activity grouping for children with direct cause epilepsy, child (0-14 years) drowning deaths. Total population survey, Australia, 2002/03-2011/12 ( $n=16)$

\begin{tabular}{|c|c|c|c|c|c|c|}
\hline & & \multicolumn{4}{|c|}{ Activity grouping } & \multirow[b]{2}{*}{ Total } \\
\hline & & Bathing & $\begin{array}{l}\text { Human powered } \\
\text { watercraft }\end{array}$ & $\begin{array}{l}\text { Swimming, paddling or } \\
\text { wading }\end{array}$ & $\begin{array}{l}\text { Walking/ playing near } \\
\text { water/ fell-in }\end{array}$ & \\
\hline \multirow[t]{5}{*}{ Location grouping } & Bathtub/spa bath & 5 & 0 & 0 & 0 & 5 \\
\hline & Beach & 0 & 1 & 1 & 0 & 2 \\
\hline & Lake/dam/lagoon & 0 & 0 & 1 & 1 & 2 \\
\hline & River/creek/stream & 0 & 0 & 2 & 0 & 2 \\
\hline & Swimming pool & 0 & 0 & 3 & 2 & 5 \\
\hline Total & & 5 & 1 & 7 & 3 & 16 \\
\hline
\end{tabular}

medical condition due to the autopsy document not being available, no mention being made of pre-existing medical conditions in the case documentation or that the parents did not want an autopsy to be undertaken. There were also six cases associated with a mass flooding and casualty event in the 2011/12 financial year where autopsies were not undertaken.

This study examined fatal drownings only; it should be noted that it is not known if the non-epilepsy chronic medical condition related non-fatal drownings have higher rates of severe morbidity. Studies of this nature of necessity depend on the subjective assignment of causal roles leading to injury. We believe that the expertise of the two experienced reviewers (paediatrician and neurologist, and safety analysis expert) provide current best subjective review of such causality.

\section{CONCLUSION}

There are nuances in the relationship between pre-existing chronic illness and the risk of childhood drowning. This study shows that the mathematical risks of aquatic activities are not dangerously increased in children with pre-existing medical conditions, when compared with the baseline population. Awareness of prevention strategies and the need to ensure heightened vigilance of children with pre-existing medical conditions, particularly those with epilepsy, is required. Children with pre-existing medical conditions should not be denied the joys and developmental experience of aquatic activities.

Correction notice This paper has been amended since it was published Online First. Owing to a scripting error, some of the publisher names in the references were replaced with 'BMJ Publishing Group'. This only affected the full text version, not the PDF. We have since corrected these errors and the correct publishers have been inserted into the references.

Acknowledgements This research is supported by the Royal Life Saving Society - Australia to aid in the reduction of drowning. Research at the Royal Life Saving Society - Australia is supported by the Australian Government.

Contributors RCF and JHP conceived the study. AEP sourced the data. JHP and RCF reviewed the medical details of each case. JHP and RCF formulated an interpretive judgement concerning whether the pre-existing medical condition was a direct cause, compromised a fatal drowning or was incidental. RCF conducted the analysis and wrote the manuscript. JHP assisted in the analysis and reviewed the manuscript. AEP reviewed the manuscript.

Disclaimer The lead author, RCF, affirms that the manuscript is an honest, accurate and transparent account of the study being reported, that no important aspects of the study have been omitted and that any discrepancies from the study as planned (and if relevant, registered) have been explained.

Competing interests None declared.

Patient consent Victims are deceased and data is stored by the data custodians, the Australian National Coronial Information System (NCIS). Access to researchers is governed under strict ethical protocols.

Ethics approval Department of Justice Human Research Ethics Committee.
Provenance and peer review Not commissioned; externally peer reviewed.

Data sharing statement With respect to the data set underlying this research, these data are available on request. However, as the data have been accessed via a third party (coronial data), ethical approval and permission from the data custodians, the Australian National Coronial Information System (NCIS) is required before the authors are able to provide their data set to the person inquiring. There are strict ethical restrictions around the use of these data, and it can therefore not be sent to a public repository. Once ethical approval and permission from the NCIS as data custodians has been achieved, researchers can contact richard.franklin@jcu.edu.au to gain access to the data.

(C) Article author(s) (or their employer(s) unless otherwise stated in the text of the article) 2017. All rights reserved. No commercial use is permitted unless otherwise expressly granted.

\section{REFERENCES}

1 Handley AJ. Drowning. BMJ 2014;348:bmj.g1734.

2 World Health Organization. Global Report on Drowning: preventing a leading killer. Geneva: World Health Organization, 2014

3 Franklin RC, Scarr JP, Pearn JH. Reducing drowning deaths: the continued challenge of immersion fatalities in Australia. Med J Aust 2010;192:123-6.

4 Bugeja L, Franklin RC. An analysis of stratagems to reduce drowning deaths of young children in private swimming pools and spas in Victoria, Australia. Int J Inj Contr Saf Promot 2013;20:282-94.

5 Pearn JH, Nixon J. An analysis of the causes of freshwater immersion accidents involving children. Accident Analysis \& Prevention 1979;11:173-8.

6 Pearn J, Nixon J. Bathtub immersion accidents involving children. Med J Aust 1977;1:211.

7 Franklin RC, Pearn JH. Drowning for love: the aquatic victim-instead-of-rescuer syndrome: drowning fatalities involving those attempting to rescue a child. J Paediatr Child Health 2011;47:44-7.

8 Bugeja L, Franklin RC. An analysis of stratagems to reduce drowning deaths of young children in private swimming pools and spas in Victoria, Australia. Int J Inj Contr Saf Promot 2013;20:1-13.

9 Peden $A E$, Franklin RC, Leggat PA. Fatal river drowning: the identification of research gaps through a systematic literature review. Inj Prev 2016;22:202-9.

10 Pearn JH, Franklin RC. Disability and drowning: personal Experiences, Research, and practicalities of adapted aquatics. Int J Aquatic Res Edu 2013;7.

11 Drowning PJ. The critically ill child diagnosis and management. 3rd ed. Philadephia: WB Sauders Co, 1985:129-56.

12 Bell GS, Gaitatzis A, Bell CL, et al. Drowning in people with epilepsy: how great is the risk? Neurology 2008;71:578-82.

13 Diekema DS, Quan L, Holt VL. Epilepsy as a risk factor for submersion injury in children. Pediatrics 1993;91:612-6.

14 Kemp AM, Sibert JR. Epilepsy in children and the risk of drowning. Arch Dis Child 1993;68:684-5.

15 Pearn JM. Epilepsy and drowning in childhood. Br Med J 1977;1:1510-1.

16 Pearn J, Bart R, Yamaoka R. Drowning risks to epileptic children: a study from Hawaii. Br Med J 1978;2:1284-5.

17 Royal Life Saving Society - Australia. National Drowning Report 2013. Secondary National Drowning Report 2013, 2013.

18 Quan L, Cummings P. Characteristics of drowning by different age groups. Inj Prev 2003;9:163-8.

19 Hwang V, Shofer FS, Durbin DR, et al. Prevalence of traumatic injuries in drowning and near drowning in children and adolescents. Arch Pediatr Adolesc Med 2003:157:50.

20 Lippmann JM, Pearn JH. Snorkelling-related deaths in Australia, 1994-2006. Med J Aust 2012;197:230-2. 
21 Australian Institute of Health Welfare. A Picture of Australia's Children 2009 Canberra: AlHW, 2009

22 Australian Institute of Health and Welfare. Selected chronic diseases among Australia's children. Bulletin Australian Institute of Health and Welfare 2005;29 http:// www.aihw.gov.au/WorkArea/DownloadAsset.aspx?id=6442453396.

23 Australian Bureau of Statistics. A snapshot, 2004-05. Health of Children in Australia, 2007. http://www.abs.gov.au/ausstats/abs@.nsf/mf/4829.0.55.001/\#. (accessed 10 Feb 2014).

24 Australian Institute of Health and Welfare. Part II: 4. morbidity. A picture of Australia's children. Canberra: AlHW, 2005:17-27.

25 van Beeck EF, Branche CM, Szpilman D, et al. A new definition of drowning: towards documentation and prevention of a global public health problem. Bull World Health Organ 2005:83:853-6.

26 National Coroners' Information System. History [NCIS]. Secondary history [NCIS]. 2014 http://www.ncis.org.au/data-collection/history/.

27 Australian Institute of Health and Welfare. Children with disabilities in Australia. AlHW cat no DIS 38. Canberra: AlHW, 2004:17-27.

28 Australian Institute of Health and Welfare. A picture of Australia's children 2009. Cat no PHE 112. Canberra: AlHW, 2009:18-19.

29 Australian Institute of Health and Welfare. A Picture of Australia's Children 2012 Canberra: AlHW, 2012

30 Franklin RC, Peden AE, Hodges S, et al. Learning to swim - What influences success? Int J Aquatic Res Edu 2015;9:220-40.
31 Kaye HS, Kang T, LaPlante MP. Mobility device use in the United States: national Institute on Disability and Rehabilitation Research, US Department of Education, 2000.

32 IBM SPSS Statistics for Windows, Version 22.0 [program]. Armonk, NY: IBM Corp, 2013

33 MEDCALC. Medcalc - Realtive risk calculator. secondary medcalc - Realtive risk calculator. 2017 https://www.medcalc.org/calc/relative_risk.php.

34 Schyllander J, Janson S, Nyberg C, et al. Case analyses of all children's drowning deaths occurring in Sweden 1998-2007. Scand J Public Health 2013;41:174-9.

35 Quan L, Cummings P. Characteristics of drowning by different age groups. Inj Prev 2003:9:163-8.

36 Lee LC, Harrington RA, Chang JJ, et al. Increased risk of injury in children with developmental disabilities. Res Dev Disabil 2008;29:247-55.

37 Albertella L, Crawford J, Skinner JR. Presentation and outcome of water-related events in children with long QT syndrome. Arch Dis Child 2011:96:704-7.

38 Thompson DC, Rivara FP. Pool fencing for preventing drowning in children. Cochrane Database Syst Rev 2000: CD001047.

39 Marchant J, Cheng NG, Lam LT, et al. Bystander basic life support: an important link in the chain of survival for children suffering a drowning or near-drowning episode. Med J Aust 2008;188:484-5.

40 Moran K, Quan L, Franklin R, et al. Where the evidence and expert Opinion Meet: a review of Open-Water Recreational Safety Messages. Int J Aquatic Res Edu 2011;5:251-70.

41 Guerrini R. Epilepsy in children. The Lancet 2006:367:499-524. 